\title{
Anaphylaxis caused by stings from the Solenopsis invicta, lava-pés ant or red imported fire ant*
}

\author{
Vidal Haddad Junior ${ }^{1}$
}

Carlos Eduardo Larsson ${ }^{2}$

DOI: http:/ /dx.doi.org/10.1590/abd1806-4841.20153420

\begin{abstract}
A bstract: Ants are social insects with species of medical interest, such as the fire ants (Solenopsis sp.). The sting causes inflammation, vesicles and sterile pustules, which may cause allergic phenomena and even anaphylactic shock. We describe a patient who suffered a large number of stings and an episode of syncope with fall in blood pressure and complete regression of symptoms after resuscitation and medication for anaphylaxis. Considering the clinical manifestations and images of wheals and blisters on the patient's feet at the time of syncope, this report should serve as a warning for the diagnosis and treatment of this condition and even for counseling and prevention regarding patients exposed to this risk.
\end{abstract}

Keywords: Anaphylaxis; Ant venoms; Ants; Brazil; Immediate hypersensitivity

\section{INTRODUCTION}

Ants are social insects that include species of medical interest, such as the genera Paraponera (tocandiras or bullet ants), Pseudomirmex (novice ants) and lava-pés ants or red imported fire ants (RIFA), of the Solenopsis genus (Figure 1). ${ }^{1-5}$ All these genera sting through abdominal stingers and inject venoms. The tocandiras and novice ants cause intensely painful manifestations and the IFA, which attack massively to defend their hives, provoke an instant wheal with vesicles that evolves into sterile pustules within approximately 24 hours (Figure 1). The process is accompanied by a burning sensation and local pain, and is precipitated by a venom of alkaloid components, such as Solenopsin A, with necrotoxic, hemolytic, insecticidal, and antibiotic properties. $^{4}$

The red lava-pés ant (Solenopsis invicta) is originate from the Pantanal region (Mato Grosso and Mato Grosso do Sul states, Brazil), having spread throughout Brazil and other countries (in the USA, they were introduced by around the 1950s, occupying vast areas; they are considered a pest to be controlled).${ }^{1,4}$

Envenomations are accompanied by burning, pain and secondary infections. Occasionally allergic phenomena of varying severity are seen, which may progress to anaphylactic shock. . $^{5-10}$

Anaphylaxis is a severe, potentially lifethreatening allergic reaction. It can occur within seconds or minutes following exposure to an antigen to which the victim is allergic. There is a massive discharge of chemical mediators from mast cells and basophiles, provoking a drop in arterial pressure, edema of the airways (angioedema), urticaria, gastrointestinal symptoms, including cramps, nausea and vomiting, syncope and occasionally death. Certain antigens are most commonly associated with anaphylaxis, such as some foods of animal origin (crustaceans) and hymenoptera venoms. Treatment consists of epinephrine, corticosteroids and antihistaminic drugs, and it should be initiated as early as possible, due to the risk of death. Some studies even point to an index of allergic phenomena similar to those observed in bee stings, which are also hymenoptera. ${ }^{9-10}$ A survey of 1,286 practitioners in South Carolina (USA) (population of 4 million), where fire ants are prominent, estimated that over 33,000 people ( 94 per 10,000 population) seek medical consultation annually for RIFA stings, of which 660 (1.9

Received on 27.02.2014

Approved by the Advisory Board and accepted for publication on 02.04.2014

Work performed at the Faculdade de Medicina de Botucatu - Universidade Estadual Paulista "Júlio de Mesquita Filho" (Unesp) e Faculdade de Medicina Veterinária e Zootecnia da Universidade de São Paulo (USP) - São Paulo (SP), Brasil.

Financial Support: None.

Conflict of Interest: None.

Universidade Estadual Paulista "Júlio de Mesquita Filho" (Unesp) - Botucatu (SP), Brazil.

Universidade de São Paulo (USP) - São Paulo (SP), Brazil.

(C)2015 by Anais Brasileiros de Dermatologia 

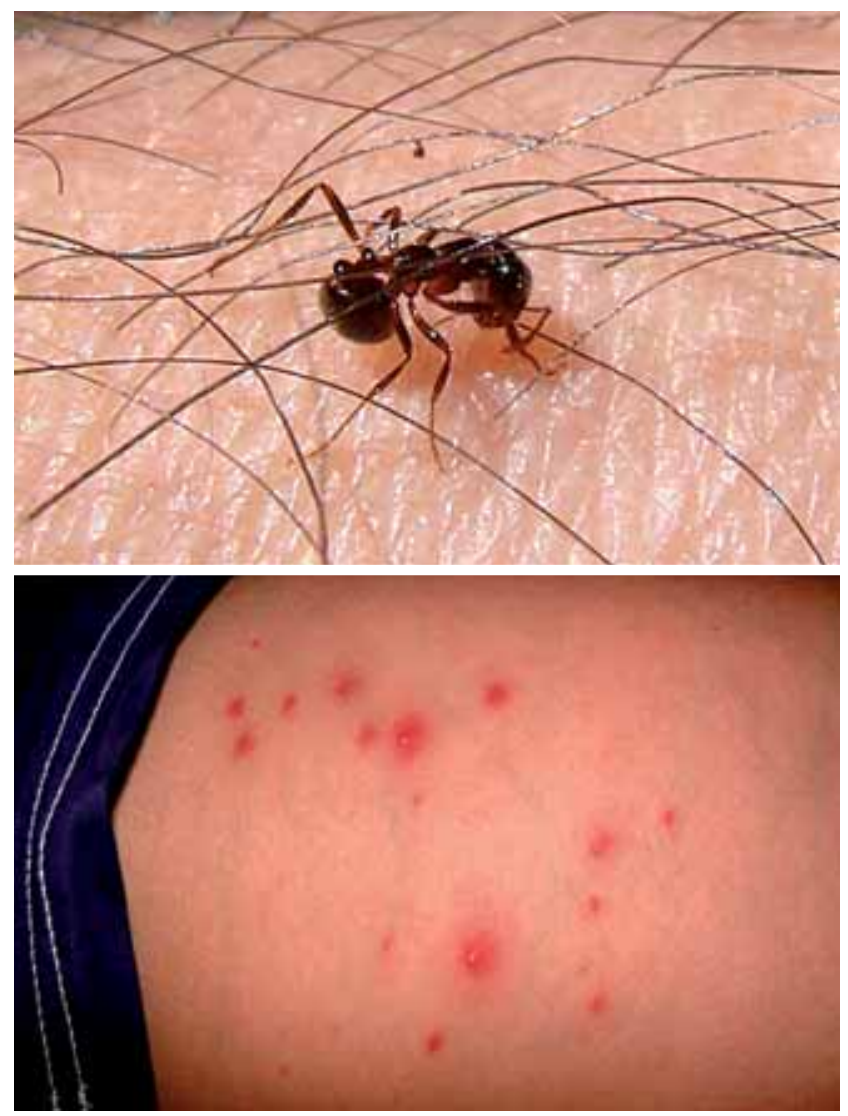

Figure 1: Solenopsis invicta, the lava-pés or red imported fire ant (above) and typical pustules caused by the ants' stings per 10,000 population) are treated for anaphylaxis. ${ }^{9} \mathrm{~A}$ study conducted at the Wilford Hall Medical Center (Air Force hospital) allergy clinic in San Antonio has reported that out of 11 patients with IFA sensitivity who refused immunotherapy, six received subsequent field stings and all suffered from anaphylaxis. ${ }^{10}$

\section{CASE REPORT}

The patient is a woman, aged 42, from São Paulo City, Brazil. She reported that after a walk at a sporting event on the São Paulo University campus, she stepped on an anthill and felt pain and burning. Many ants covered her feet and legs and she immediately removed her sports shoes, which were also enveloped by ants.

Approximately 5-10 minutes after the stings, she felt strong vertigo. Her sister, who was present, reported that the victim did not respond to calls; she bowed down until she lay on the floor. A nearby campus guard realized the gravity of the situation and performed cardiac massages and mouth-to-mouth respiration for about 10 minutes. Later, he informed that the patient had no pulse, immeasurable blood pressure, glassy eyes, dry mouth and intense paleness. An on-duty ambulance at a sporting event transferred the (still unconscious) victim to the University Hospital on the campus. Upon regaining consciousness, the patient felt severe abdominal cramps and pain in the right leg, which had received the highest number
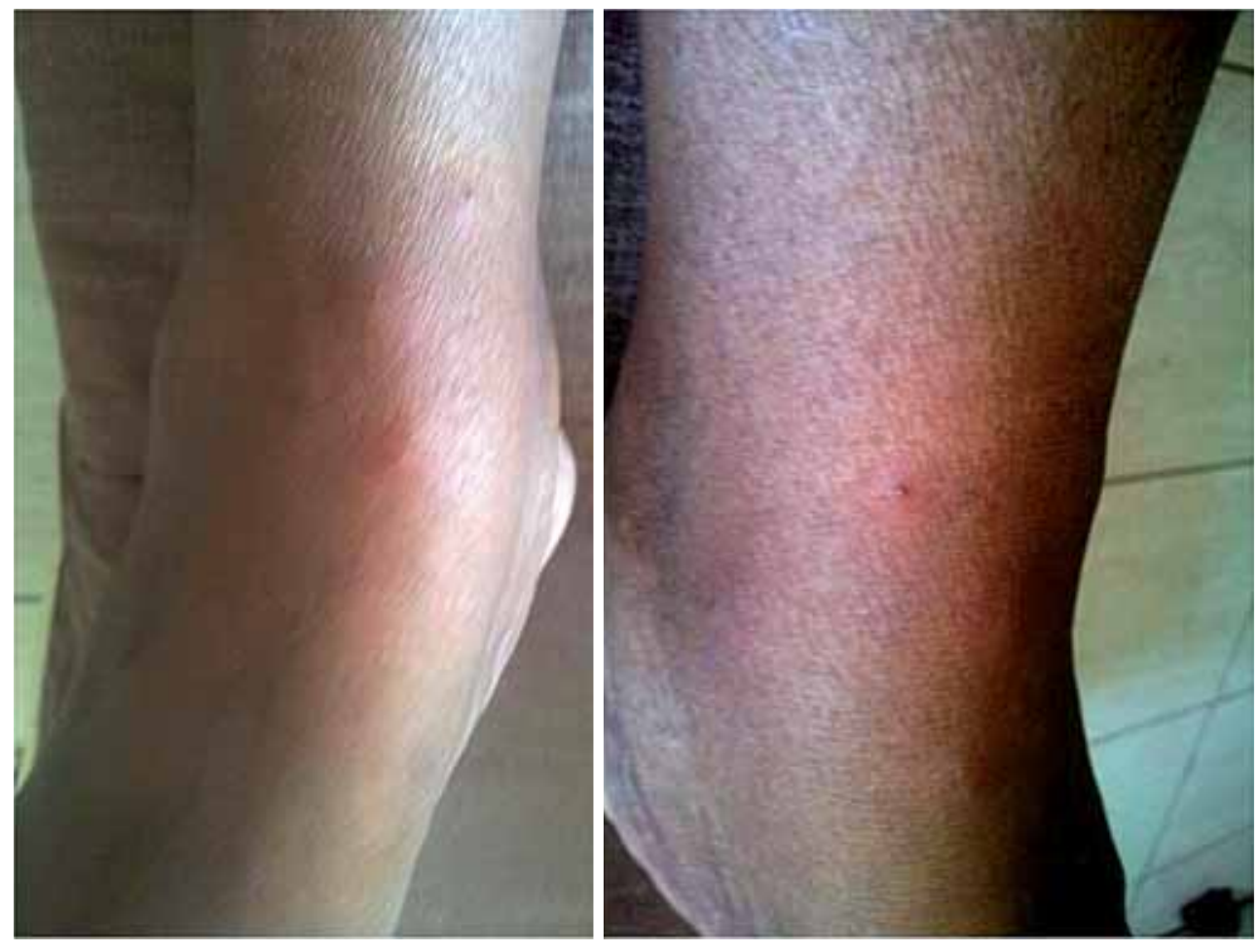

\section{Figure 2:}

Wheals and vesicles in the patient, recorded on the day the stings occurred. There is inflammation on the sting sites 


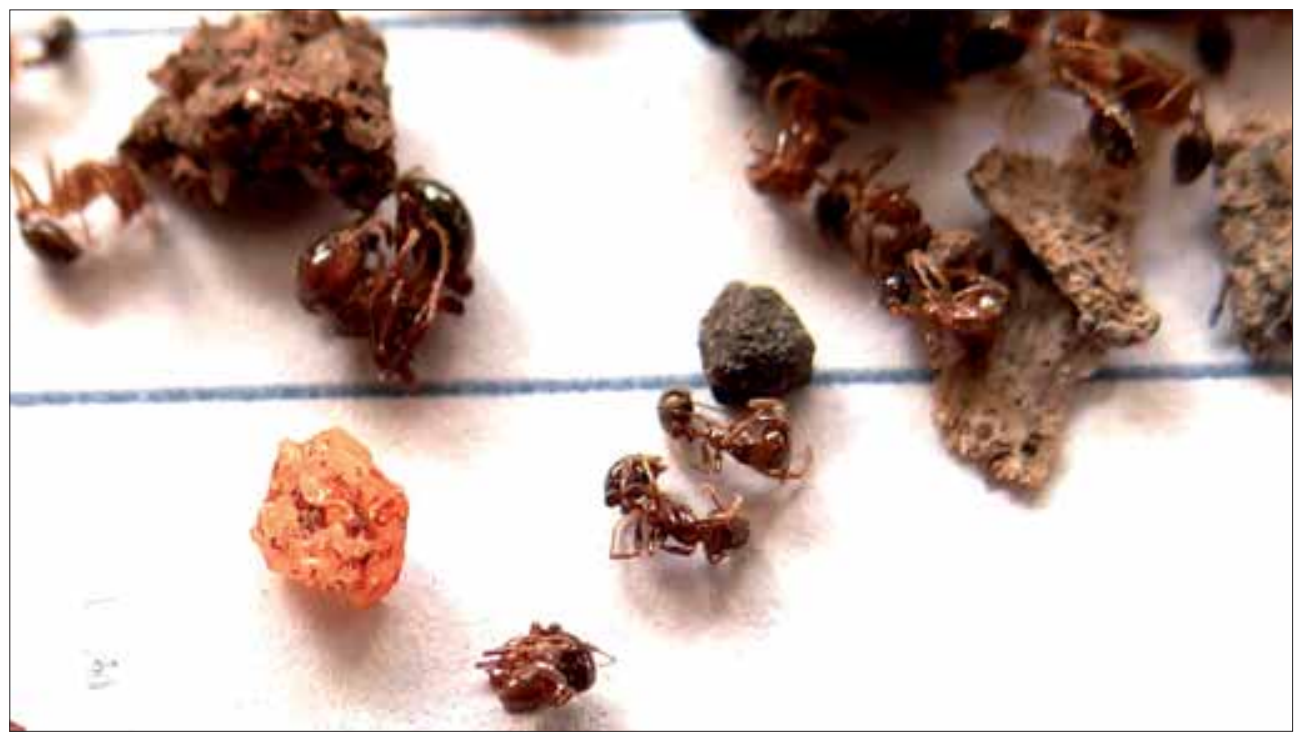

Figure 3: Specimens of Solenopsis invicta collected from the anthill the patient stepped on, prior to anaphylactic manifestations of stings, manifesting as urticariform plaques and vesicles (Figure 2). There was no information about the skin lesions, other than on the sting area. She was treated with saline, epinephrine and antihistamines, with complete regression of the symptoms.

Due to family history of ischemic heart disease, the patient underwent an EKG examination to measure creatine phosphokinase levels (CPK-MB fraction), a marker of cardiac necrosis and infarction. The ECG was normal and CPK - MB showed no elevated titers. Approximately 12 hours later, she was released to seek guidance from a general practitioner for follow-up and clarification regarding the manifestations.

Subsequently, the patient underwent an echocardiogram, which showed a slight mitral regurgitation, as well as a Holter exam (sinusal rhythm, with rare supraventricular extrasystolic arrhythmia and a single ventricular extrasystole). The neurological examination was normal. At present, she exhibits no manifestations or sequel, and will undergo testing for allergy to Hymenoptera venoms. Her allergy history to bees and ants was unclear prior to the episode. The ants collected from the same anthill the patient stepped on was identified as Solenopsis invicta, the red imported fire ant (Figure 3).

\section{DISAUSSION}

The patient endured numerous bites and had one episode of syncope, involving a fall in blood pressure without posterior cardiac or neurological manifestations, and complete regression of the subsequent reactions after resuscitation maneuvers and medication for anaphylaxis. At the time of the episode, she did not experience electrocardiographic changes or elevated enzymes, which mischaracterizes an ischemic myocardial episode, while the Holter exam showed no cardiac arrhythmias that could justify the syncope. The normal neurological examination also contributed to the final hypothesis, as well as abdominal cramps, which are manifestations of anaphylaxis.

It is a fairly common phenomenon in Hymenoptera stings, and particularly so in RIFA stings. ${ }^{5-10}$ The anaphylactic shock caused by IFA stings is the main hypothesis in this case, given the clinical manifestations and images of wheals and vesicles on the patient's feet upon the syncope. The case should serve as a warning regarding the correct diagnostic hypothesis and treatment adopted by medical teams, as well as guidance and prevention for patients exposed to this risk. 


\section{REFERENCES}

1. Haddad Jr V, Cardoso JLC, França FOS, Wen FH. Accidents by ants: a dermatological problem. An Bras Dermatol. 1996;71:527-30.

2. Haddad Junior V, Cardoso JL, Moraes RH. Description of an injury in a human caused by a false tocandira (Dinoponera gigantea, Perty, 1833) with arevision on folkloric, pharmacological and clinical aspects of the giant ants of the genera Paraponera and Dinoponera (sub-family Ponerinae). Rev Inst Med Trop Sao Paulo. 2005 Jul-Aug;47(4):235-8.

3. Haddad Junior V, Bicudo LR, Fransozo A. The Triplaria tree (Triplarisspp) and Pseudomyrmex ants: a symbiotic relationship with risks of attack for humans. Rev Soc Bras Med Trop. 2009;42:727-9.

4. Vinson SB, Sorenson AA. Imported Fire Ants: Life History and Impact. Austin: Texas Department of Agriculture; 1986. 28 p.

5. La Shell MS, Calabria CW, Quinn JM. Imported fire ant field reaction and immunotherapy safety characteristics: the IFACS study. J Allergy Clin Immunol. 2010;125:1294-9.

6. Lee JK, Betschel SD.A case of the first documented fire ant anaphylaxis in Canada. Allergy Asthma Clin Immunol. 2013;9:25.

7. Stafford CT. Hypersensitivity of fire ant venom. Ann Allergy Asthma Immunol. 1996;77:87-95

8. Solley GO, Vanderwoude C, Knight GK. Anaphylaxis due to Red Imported Fire Ant sting. Med J Aust. 2002;176:521-3.

9. Caldwell ST, Schuman SH, Simpson WM Jr. Fire ants: a continuing community health threat in South Carolina. J S C Med Assoc. 1999;95:231-5.

10. Freeman TM, Hylander R, Ortiz A, Martin ME. IFA Immunotherapy: Effectiveness of Whole Body Extracts. J Allergy Clin Immunol. 1992;90:210-5.

\author{
M AILING ADDRESS: \\ Vidal H addad Junior \\ Caixa Postal 557 \\ 18618-970 - Botucatu - SP \\ Brazil \\ E-mail: haddadjr@fmb.unesp.br
}

H ow to cite this article: Haddad V Jr, Larsson CE. Anaphylaxis caused by stings from the Solenopsis invicta, lavapés ant or red imported fire ant. An Bras Dermatol. 2015;90(3 Suppl 1):S22-5. 